\title{
Prevalence and drug resistance pattern of Listeria monocytogenes among pregnant women in Tigray region, Northern Ethiopia: a cross-sectional study
}

\author{
Letemichael Negash Welekidan ${ }^{1 *}$, Yemane Weldu Bahta ${ }^{1}$, Mebrihit Gebremeskel Teklehaimanot ${ }^{2}$, \\ Getahun Kahsay Abay', Araya Gebreyesus Wasihun', Tsehaye Asmelash Dejene 1,3, Saravanan Muthupandian?', \\ Tadele Araya Mezgebo ${ }^{1}$ and Amlsha Kahsay Hagos ${ }^{1}$
}

\begin{abstract}
Objective: The aim of this study was to determine the prevalence and antimicrobial susceptibility test of Listeria monocytogenes among pregnant women in Tigray region, Ethiopia.

Results: The overall prevalence of $L$. monocytogenes among pregnant women was found to be $(8.5 \% ; 12 / 141)$. With regard to the socio-demographic characteristics, a high prevalence of $L$. monocytogenes was observed in the age group of $20-24$ years (18.6\%; 8/43), rural dwellers (10\%; 3/30), secondary school (9.6\%; 5/52), and housewives (11.4\%;10/88). A high drug resistance rate was observed to penicillin G (66.7\%), clindamycin (66.7\%), amoxicillin (50\%) and vancomycin (50\%). However, isolates were relatively sensitive to ciprofloxacin (75\%), erythromycin (75\%), trimethoprim/sulphamethaxazole (66.7\%) and chloramphenicol (60\%).
\end{abstract}

Keywords: Listeria monocytogenes, Pregnant women, Prevalence, Drug resistance, Tigray Region, Ethiopia

\section{Introduction}

Listeriosis caused by Listeria monocytogenes, is one of the important bacterial zoonotic infections worldwide [1]. This causes severe and life-threatening infection mainly in high-risk groups such as pregnant women, neonates, elderly and immunocompromised patients [2]. The fatality rate in high-risk groups can be up to $30 \%$ [3]. Studies revealed that listeriosis occurs 20 times more in pregnant women than the general people [4-7]. Teresa et al. [8], has also reported that $43 \%$ of the listeriosis cases conducted in 20 countries were related with pregnancy. In the United States listeriosis caused approximately 2500 serious illnesses and 500 deaths annually [9], and $17 \%$ of cases were associated with pregnancy [10].

*Correspondence: letemichael.negash@mu.edu.et

${ }^{1}$ Department of Medical Microbiology and Immunology, Division of Biomedical Sciences, College of Health Science, Mekelle University, P.O.Box:1871, Mekelle, Tigray, Ethiopia

Full list of author information is available at the end of the article
Listeriosis in pregnant women is usually asymptomatic or with nonspecific clinical symptoms such as flu-like symptoms. However, it can cause abortion, preterm delivery, fetal death, or neonatal morbidity in the form of septicaemia, meningitis and encephalitis without being detected [8]. Approximately $20 \%$ of pregnancies complicated by listeriosis end in spontaneous abortion or stillbirth, and two-thirds of surviving infants develop clinical neonatal listeriosis such as pneumonia, sepsis, and it accounts for $20 \%$ of all cases of neonatal meningitis $[7,11-14]$. The mortality rate for infants born alive approaches $20 \%$ and the frequency of abortion and stillbirth increases the overall mortality rate to more than $50 \%$ [8]. Previous studies reported drug resistance for $L$. monocytogenes like penicillin G, cefotaxim, gentamicin [15-18].

Foods which are commonly contaminated by Listeria such as ready-to eat foods, uncooked meats, fish, uncooked vegetables, unpasteurized milk and milk 
products should not be eaten by pregnant women, and are suggested to undergo screening for the bacteria [19]. Despite the potential threat to human health posed by this pathogen, there is scarcity of data on listeriosis among pregnant women in Ethiopia, particularly in Tigray there is no published data on pregnant women. Therefore, the aim of this study was to determine the prevalence and antimicrobial susceptibility test of $L$. monocytogenes among pregnant women attending antenatal care of Mekelle Hospital and Ayder comprehensive specialized hospital.

\section{Main text \\ Materials and methods Study area and design}

A hospital based, cross-sectional study was conducted from February to May 2016 at Mekelle hospital and Ayder comprehensive specialized hospital, Northern Ethiopia. Mekelle is located at $783 \mathrm{~km}$ north of Addis Ababa, the capital of Ethiopia. Mekelle, which is the capital city of Tigray regional state, has a total population of 307,305 [20]. A total of 141 pregnant women who attended at the hospitals antenatal care with a flue like signs and symptoms were included in the study.

\section{Eligibility criteria}

Pregnant women having flue like signs and symptoms such as fever, backache, headache, vomiting/diarrhea, muscle pains and sore throat was included in the study.

\section{Sample size and sampling technique}

A total of 141 pregnant women who fulfil the eligibility criteria were consecutively recruited from February to May 2016.

\section{Dependent variables}

Prevalence of L. monocytogenes and antimicrobial susceptibility test.

\section{Independent variables}

Socio-demographic variables.

\section{Data and specimen collection}

Clinical and demographic data were collected using structured questionnaire. After written informed consent obtained from study participant, $5 \mathrm{ml}$ blood sample was collected aseptically, transferred into a sterile $0.6 \%$ tryptose soy broth (Oxoid, UK) in a screw caped test tube, and transported to Ayder microbiology laboratory within $1 \mathrm{~h}$.

\section{Culture and identification}

After overnight incubation on Tryptic soy broth (Oxoid, UK) plus $0.6 \%$ yeast extract enrichment broth. The suspected growth were sub-cultured to palkam agar media and listeria selective agar (Oxoid, UK), and incubated at $35{ }^{\circ} \mathrm{C}$ for $24 \mathrm{~h}$. The green shiny colonies with diffuse black shadow around them on palkam agar and yellow small colonies on listeria selective agar were suspected to be Listeria. Suspected colonies were further identified using gram stain, catalase test, motility test, beta haemolysis on blood agar, CAMP test, fermentation of sugars (xylose, rhamnose, mannitol and methyl D-mannopyranoside), oxidase test and methyl red-voges proskauer (MR-VP) tests.

\section{Antimicrobial susceptibility testing}

A standard Kirby-Bauer disk diffusion method was used [21]. Inoculum suspension was prepared using sterile saline to obtain turbidity comparable to 0.5 McFarland standards and Sterile cotton swab was dipped, rotated across the wall of the tube to avoid excess fluid and was evenly inoculated on MullerHinton agar (Oxoid, UK) and the antibiotic discs were placed on Muller-Hinton agar plates.

The following antibiotics were tested: penicillin $G$ (10U), trimethoprim/sulphamethaxazole $(25 \mu \mathrm{g})$, ciprofloxacin $(5 \mu \mathrm{g})$, amoxicillin $(20 \mu \mathrm{g})$, erythromycin $(15 \mu \mathrm{g})$, clindamycin $(2 \mu \mathrm{g})$ and vancomycin $(30 \mu \mathrm{g})$ (Oxoid, UK).

\section{Quality assurance}

Standard operational procedures were followed and $L$. monocytogenes (ATCC 7644) was used as the reference strain.

\section{Data analysis}

Data were analyzed using SPSS version 20. Descriptive statistics and binary logistic regression were employed. Binary logistic regression was used to show the association of each variable with the dependent variable. P-value $<0.05$ with $95 \%$ confidence interval was considered statistically significant.

\section{Results}

In the present study, 141 pregnant women enrolled. The mean age of participants was $26.23(+5.42 \mathrm{SD})$. Of the total, 84 (59.6\%), 111 (78.7\%), 78 (55.3\%), 88 (62.4\%) and 67 (47.5) participants were in the age range 20-29, urban dwellers, attended secondary school and above, house wives and had fever/headache, respectively (Table 1). 
Table 1 Association of socio-demographic characteristics of pregnant women $(n=141)$ with L. monocytogenes in Mekelle Hospital and Ayder Comprehensive Specialized Hospital, Tigray, Ethiopia [Feb-May, 2016]

\begin{tabular}{|c|c|c|c|c|c|c|}
\hline \multirow[t]{2}{*}{ Variable } & \multirow[t]{2}{*}{ Frequency } & \multirow[t]{2}{*}{ Percent (\%) } & \multicolumn{2}{|c|}{ L. monocytogenes } & \multirow[t]{2}{*}{ P-value } & \multirow[t]{2}{*}{ COR $(95 \% \mathrm{Cl})$} \\
\hline & & & Positive & Negative & & \\
\hline \multicolumn{7}{|l|}{ Age (years) } \\
\hline $15-24$ & 58 & 41.1 & $8(13.8)$ & $50(86.2)$ & & 1 \\
\hline $25-34$ & 68 & 48.2 & $3(4.4)$ & 65 (95.6) & 0.077 & $3.47(0.88-13.74)$ \\
\hline $35-44$ & 15 & 10.6 & $1(6.7)$ & $14(93.3)$ & 0.465 & $2.24(0.26-19.46)$ \\
\hline \multicolumn{7}{|l|}{ Residence } \\
\hline Urban & 111 & 78.7 & $9(8.1)$ & $102(91.9)$ & & 1 \\
\hline Rural & 30 & 21.3 & $3(10)$ & $27(90)$ & 0.742 & $0.79(0.20-3.13)$ \\
\hline \multicolumn{7}{|l|}{ Educational status } \\
\hline Unable to read and write & 14 & 9.9 & $1(7.1)$ & $13(92.9)$ & 0.95 & $1.08(0.09-13.1)$ \\
\hline Read and write & 13 & 9.2 & $1(7.7)$ & $12(92.3)$ & 1 & $1(0.08-12.16)$ \\
\hline Elementary school & 36 & 25.5 & $3(8.3)$ & $33(91.7)$ & 0.927 & $0.92(0.14-5.92)$ \\
\hline Secondary school & 52 & 36.9 & $5(9.6)$ & $47(90.4)$ & 0.78 & $0.78(0.14-4.34)$ \\
\hline College level & 26 & 18.4 & $2(7.7)$ & $24(92.3)$ & & 1 \\
\hline \multicolumn{7}{|l|}{ Occupation } \\
\hline Government employee & 13 & 9.2 & $1(7.7)$ & $12(92.3)$ & & 1 \\
\hline Merchant & 20 & 13.5 & $1(5)$ & $19(95)$ & 0.753 & $1.58(0.09-27.77)$ \\
\hline Daily worker & 21 & 14.9 & $1(4.8)$ & $20(95.2)$ & 0.727 & $1.67(0.1-29.18)$ \\
\hline House wife & 87 & 62.4 & $9(10.3)$ & 78 (89.7) & 0.767 & $0.72(0.08-6.22)$ \\
\hline
\end{tabular}

\section{Prevalence of Listeria monocytogenes}

The overall prevalence of L. monocytogenes among pregnant women was $8.5 \%(12 / 141)$. A high prevalence of $L$. monocytogenes was observed in the age group of $15-24(13.8 \%$; $8 / 58)$, rural dwellers $(10 \%$; $3 / 30)$, those who attended secondary school $(9.6 \% ; 5 / 52)$, and housewives $(10.3 \%$; $9 / 87)$ respectively, but not statistically significant (Table 1$)$.

\section{Clinical data of the pregnant women}

Study participants with fever $(8 ; 11.9 \%)$, headache $(6$; $9 \%)$, muscle pain $(3 ; 7.9 \%)$, vomiting $(2 ; 11.1 \%)$ and diarrhea $(2 ; 28.6 \%)$ had L. monocytogenes infection.

\section{Risk factors for Listeria monocytogenes infection}

Pregnant women who had a frequent habit of consuming unpasteurized milk were 2.9 times at risk for L. monocytogenes infection, but it was not statistically significant $(\mathrm{COR}=2.9(10.57-0.79), \mathrm{P}=0.108)$. On the other hand, consumption of fish, meat and uncooked vegetables were not found as risk factor for $L$. monocytogenes infection (Table 2).

\section{Antimicrobial susceptibility test of Listeria monocytogenes} Drug resistance to antibiotics like penicillin G (66.7\%), clindamycin (66.7\%), amoxicillin (50\%), and
Table 2 Association of possible risk factors for $L$. monocytogenes infection among pregnant women attending antenatal care clinics in Mekelle Hospital and Ayder Comprehensive Specialized Hospital, Tigray, Ethiopia [Feb-May, 2016]

\begin{tabular}{|c|c|c|c|c|c|}
\hline \multirow[t]{2}{*}{ Variable } & \multirow[t]{2}{*}{ Total } & \multicolumn{2}{|c|}{ L. monocytogenes } & \multirow[t]{2}{*}{ P-value } & \multirow[t]{2}{*}{ COR $(95 \% \mathrm{Cl})$} \\
\hline & & Positive & Negative & & \\
\hline \multicolumn{6}{|l|}{ Gestational age } \\
\hline 1st trimester & 65 & $6(9.2)$ & $59(90.8)$ & 0.709 & $0.73(0.14-3.85)$ \\
\hline 2nd trimester & 47 & $4(8.5)$ & $43(91.5)$ & 0.8 & $0.8(0.14-4.65)$ \\
\hline 3rd trimester & 29 & $2(6.9)$ & $27(93.1)$ & & 1 \\
\hline \multicolumn{6}{|c|}{ Frequently feeding habit } \\
\hline \multicolumn{6}{|l|}{ Packed meat } \\
\hline Yes & 1 & 0 & $1(100)$ & 1.0 & $1.515 \mathrm{E} 8(0.00)$ \\
\hline No & 140 & $12(8.6)$ & $128(91.4)$ & & 1 \\
\hline \multicolumn{6}{|l|}{ Fish } \\
\hline Yes & 6 & 0 & $6(100)$ & 0.999 & 1.576EB $(0.00)$ \\
\hline No & 135 & $12(8.9)$ & $123(91.1)$ & & 1 \\
\hline \multicolumn{6}{|c|}{ Uncooked vegetables } \\
\hline Yes & 136 & $12(8.2)$ & $124(91.8)$ & 0.999 & $0.00(0.00)$ \\
\hline No & 5 & 0 & $5(100)$ & & 1 \\
\hline \multicolumn{6}{|c|}{ Unpasteurized milk } \\
\hline Yes & 118 & $8(6.8)$ & $110(93.2)$ & 0.108 & $2.9(0.79-10.57)$ \\
\hline No & 23 & $4(17.4)$ & $19(82.6)$ & & 1 \\
\hline
\end{tabular}


vancomycin (50\%) were found to be high, whereas relatively low rate of drug resistance were observed to the antibiotics chloramphenicol (40\%), trimethoprim/ sulphamethaxazole (33.3\%), ciprofloxacin (25\%) and erythromycin (25\%) (Fig. 1).

\section{Discussion}

In this study, a considerable prevalence of L. monocytogenes was found among pregnant women. This may cause mild infection to the pregnant mothers but it can be devastating to the fetus that can result to preterm delivery, stillbirth, fetal death, or a serious neonatal morbidity like septicemia, pneumonia, meningitis and encephalitis. The prevalence of this study $(8.5 \% ; 12 / 141)$ is comparable with research findings $(8.9 \%)$ done in HIV/AIDS patients in Nigeria [22] and a case report $(9.3 \% ; 11 / 118)$ in British [23]. However, it is higher than the findings from United States done among general population (4.8\%; 7/147) [10] and New England in a case series and review on pregnant women $(5.0 \%$; 11/222) [13]. However, it is lower than findings from systemic review and meta-analysis (20.7\%) [24] and a case report from Ireland in 2007 (42.9\%; 9/21) [25]. The possible explanations for the differences could be due to difference in study groups, sample size, awareness and geographic location.
The prevalence of $L$. monocytogenes among pregnant women found to be higher in the age group 20-24 years, and house wives. The possible reasons could be due to lack of awareness on the source of infection, risk of infection and preventive measures. In this study, the prevalence of L. monocytogenes was higher in the first trimester gestational period. Early gestational Listeria infection of the fetuses have lesser chance of recovery [13] than later gestations, and mostly the outcome ends up with spontaneous abortion or stillbirth [26-28]. Studies reported that the outcome of early gestational listeriosis was spontaneous abortion $(10-20 \%)$, preterm delivery (50\%), intrauterine fetal death (11\%) [28], fetal distress (34\%), and meconium staining of the amniotic fluid (75\%) [13, 28]. Even though, preterm birth is common [29], infants born at the earliest gestations have the highest mortality rate [28]. However, listeriosis mostly reported in the third trimester [30], so far, cases at earlier gestational period have been diagnosed [31, 32]. The possible reason for rarity of the incidence of listeriosis during earlier gestational period could be due to unfrequently culturing of products of conception/fetal tissue in cases of early fetal losses [33]. The other possible reason for the higher prevalence of L. monocytogenes in the first

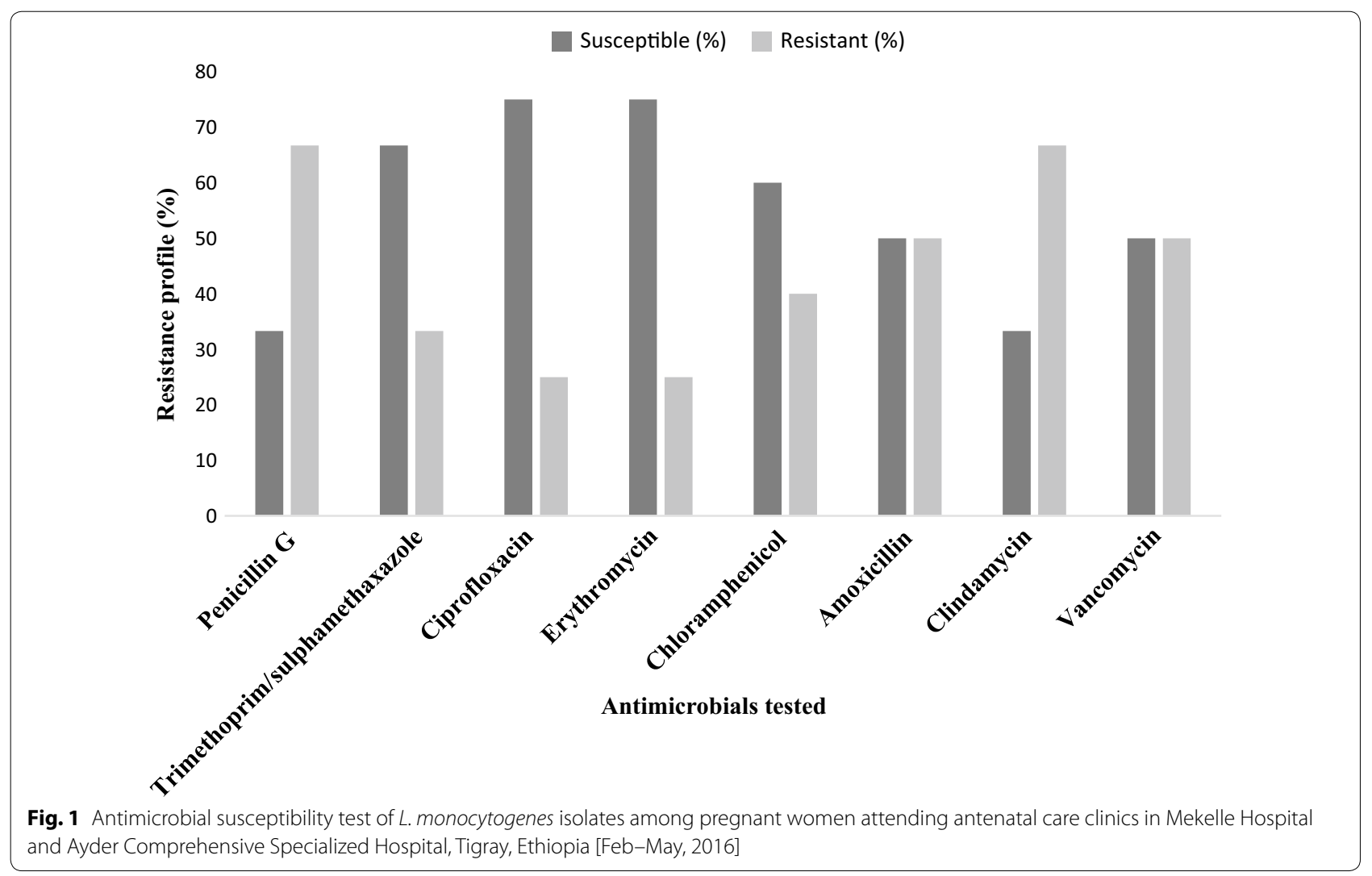


trimester gestational period could be due to other predisposing factors to the pregnant women. A report from case series and review mentioned that some pregnant women were taking immunosuppressive drugs for heart transplantation secondary to cardiomyopathy, and some pregnant women developed gestational diabetes during the first trimester of pregnancy [13].

Pregnant women who had the habit of consumption of unpasteurized milk (6.8\%) were infected with L. monocytogenes. This implies pregnant women should have to avoid foods known to be at increased risk of contamination with L. monocytogenes. Out of 142 reported cases of listeriosis in epidemics associated with contaminated Mexican-style cheese prepared from unpasteurized milk, $65.5 \%$ occurred in pregnant women [34]. Although, unpasteurized milk is a common risk factor for acquisition of listeriosis, pasteurized milk associated outbreak in Massachusetts reported that 14\% (7/49) of cases were pregnancy associated [35].

In this study, high drug resistances were observed on penicillin G (66.7\%), clindamycin (66.7\%), amoxicillin $(50 \%)$, and vancomycin (50\%). Therefore, development of drug resistance for the advisable drugs may face a great challenge in the treatment of listeriosis that can be threatening for the outcome of pregnancy. However, unlike to this study, all $L$. monocytogenes isolated from spontaneous abortion of humans in Iran were sensitive to trimethoprim and erythromycin ( $100 \%$ each) and relatively higher sensitivity to chloramphenicol (88\%) and ciprofloxacin (66.67\%) [15]. Besides, all L. monocytogenes isolated from ready to eat foods in Poland were sensitive to ciprofloxacin, chloramphenicol and trimethoprim/ sulfamethoxazole [36]. Moreover, isolates from Chinese food were highly susceptible to ciprofloxacin (90.5\%) and higher susceptibility to trimethoprim/sulfamethoxazole (57.1\%) were reported [37]. Comparing to the current study, higher drug resistance were reported from a study done on HIV/AIDS patients in Nigeria to amoxicillin (100\%), trimethoprim-sulfamethoxazole (79.3\%), chloramphenicol (62.1\%), erythromycin (48.3\%) and ciprofloxacin (31\%) [22], ciprofloxacin (37\%) resistance for isolates from Poultry in Georgia [38], and penicillin G (77.77) resistance of isolates from spontaneous abortion of humans in Iran [15]. However, lower resistance were observed for isolates from foods and human samples in Germany to erythromycin (1.9\%) and ciprofloxacin (9.7\%) [39], in China on Chinese food to clindamycin (52.4\%) [37], and chloramphenicol (11.11\%) for isolates from spontaneous abortion of humans in Iran [15]. The extensive utilization of antibiotics in human medicine, veterinary medicine and agriculture has attributed for the increasing emergence of drug resistant bacteria, including strains of Listeria spp. [40].

\section{Conclusion and recommendations}

High prevalence of $L$. monocytogenes and rate of drug resistance were found among pregnant women. Therefore, pregnant women should be aware of source of infection, preventive measures, morbidity, and mortality rates by focusing on the risks like abortion, preterm delivery and stillbirth. Active screening for L. monocytogenes infection and early treatment is also required during pregnancy to prevent the possible complications to the mother and the fetus.

\section{Limitations}

- This study did not look for the status of HIV in the study participants.

- Did not study the strains circulating in the region.

\section{Acknowledgements}

The authors are thankful to the study participants. We also thanks to Mekelle Hospital and Ayder comprehensive specialized hospital gynaecology and laboratory staffs for their collaboration during data collection.

\section{Authors' contributions}

LN involved in the conceiving and proposal design, data analysis and manuscript preparation. YW and AK involved in proposal writing, data analysis and manuscript preparation. GK, AG, TAD, SM, TA and MG contributed in the manuscript preparation and approval to the final version of this paper. All authors read and approved the final manuscript.

\section{Funding}

This study was funded by Mekelle University, College of Health Sciences (CRPO/CHS/010/08). The funder has no role in design of the study and collection, analysis, and interpretation of data and in writing the manuscript.

\section{Availability of data and materials}

The data of this study is available with the corresponding author up on request.

\section{Ethics approval and consent to participate}

Ethical approval obtained from Mekelle University College of Health Sciences, Research and Community Services Council (ERC 0691/2016). Permission also obtained from both hospital administrations. Written informed consent was obtained from study participant and their identity was kept confidential. The physician for treatment consulted participants with positive result.

\section{Consent to publish}

Not applicable.

\section{Competing interests}

The authors declare that they have no competing interests.

\section{Author details}

${ }^{1}$ Department of Medical Microbiology and Immunology, Division of Biomedical Sciences, College of Health Science, Mekelle University, P.O.Box:1871,

Mekelle, Tigray, Ethiopia. ${ }^{2}$ Department of Obstetrics and Gynaecology, School of Medicine, College of Health Sciences, Mekelle University, P.O.Box:1871, Mekelle, Tigray, Ethiopia. ${ }^{3}$ College of Health Sciences, Environmental Microbiology, Aksum University, Axsum, Ethiopia.

Received: 9 July 2019 Accepted: 13 Auqust 2019

Published online: 23 August 2019 


\section{References}

1. Bayleyegn M, Roman Y, Daniel A. Listeria monocytogenes and other Listeria species in retail meat and milk products in Addis Ababa, Ethiopia. Ethiop J Health Dev. 2004;18(3):1-5

2. Morvan A, Moubareck C, Leclercq A, Herve-Bazin M, Bremont S, et al. Antimicrobial resistance of Listeria monocytogenes strains isolated from humans in France. Antimicrob Agents Chemother. 2010:54(6):2728-31.

3. Ramaswamy V, Cresence VM, Rejitha JS, Lekshmi MU, Dharsana KS, et al. Listeria review of epidemiology and pathogenesis. J Microbiol Immunol Infect. 2007:40:4-13.

4. Vanitha J. Listeriosis in pregnancy: diagnosis, treatment, and prevention. Rev Obstet Gynecol. 2008;1(4):179-85.

5. Centers for Disease Control and Prevention. Listeriosis. Coordinating Center for Infectious Diseases/Division of Bacterial and Mycotic Diseases, Centre for Disease Control and Prevention, Atlanta, GA30033. 2005. http://www.cdc.gov/ncidod/dbmd/diseaseinfo/listeriosis. Accessed 21 Oct 2015.

6. Voelker R. Listeriosis outbreak prompts action. JAMA. 2002:288(21):26756. Population and Housing Census-2007 (PDF). FDRE Population Census Commission. Retrieved 6 October 2016.

7. Silver HM. Listeriosis during pregnancy. Obstet Gynecol Surv. 1998:53(12):737-40.

8. Teresa M, Joana S, Rui L, Paula T. Listeriosis during pregnancy: a public health concern. ISRN Obstet Gynecol. 2013;2013:6.

9. Centers for Disease Control and Prevention. Multistate outbreak of listeriosis-United States, 2000. JAMA. 2001;285(3):285-6.

10. Maho I, Janell A, Marigny K, Weidong G, Michelle S. Estimating the attack rate of pregnancy-associated listeriosis during a large outbreak. Infect Dis Obstet Gynecol. 2015. https://doi.org/10.1155/2015/201479.

11. Posfay-Barbe KM, Wald ER. Listeriosis. Pediatr Rev. 2004;25(5):151-9.

12. Braden CR. Listeriosis. Pediatr Infect Dis J. 2003:22(8):745-6.

13. Mylonakis E, Paliou M, Hohmann EL, Calderwood SB, Wing EJ. Listeriosis during pregnancy: a case series and review of 222 cases. Medicine. 2002:81(4):260-9.

14. Schuchat A. Listeriosis and pregnancy: food for thought. Obstet Gynecol Surv. 1997;52(12):721-2

15. Lida L, Jamileh N, Gholamreza I, Faramarz M, Bahram K, Laleh E, et al. Listeria monocytogenes in spontaneous abortions in humans in Iran. Afr J Microbiol Res. 2011;5(14):1990-3.

16. Prazak MA, Murano EA, Mercado I, Acuff GR. Antimicrobial esistance of Listeria monocytogenes isolated from cabbage farms and packing sheds in Texas. J Food Prot. 2002:65(11):1796-9.

17. Charpentier E, Gerbaud G, Jacquet C, Rocourt J, Courvalin P. Incidence of antibiotic resistance in Listeria species. J Infect Dis. 1995;172:277-81.

18. Poyart S, Carlier C, Cortieu AL, Courvalin P. Transterable plasmid-mediated antibiotic resistance in Listeria monocytogenes. Lancet. 1990:335:1422-6.

19. Colleen K, Jonathan B. Listeriosis in pregnancy. Survey of British Columbia practitioners' knowledge of risk factors, counseling practices, and learning needs. Can Fam Physician. 2010:56:158-66.

20. Federal Democratic Republic of Ethiopia Central Statistical Agency Population Projection of Ethiopia for All Regions At Wereda Level from 2014-2017

21. Clinical and laboratory standards institute. Performance standards for antimicrobial susceptibility testing, vol. 32, No. 1. 11 th edition. CLSI document M02-A11. Wayne: Clinical and laboratory standards institute.

22. Akano SO, Deji-Agboola AM, Oluwadun A. Listeria species and antimicrobial resistance profiles of HIV/AIDS patients in Lagos, Nigeria. NY Sci J. 2014;7(4):46-52.
23. British Columbia centre for disease control 2010 British Columbia annual summary of reportable diseases. Vancouver, BC: BC Centre for Disease Control; 2012. www.bccdc.ca/NR/rdonlyres/6F0D23A6-18E8-4983-AE53A7F0C7F0D91B/0/2010CDAnnualReportFinal.pdf. Accessed 22 Oct 2015.

24. Charline MT, Brecht D, Frederick JA, Geert V, Juanita $H$, et al. The global burden of listeriosis: a systematic review and meta-analysis. J Lancet Infect Dis. 2014;14(11):1073-82

25. Health Protection Surveillance Centre Ireland. Listeriosis and pregnancy: fact sheet. 2008.

26. Johnston WH, Morton SA, Wong MH, TE Roy. Septicaemia of the newborn due to Listeria monocytogenes. Can Med Assoc J. 1955;73:402-5.

27. Reiss HJ, Krebs A. Septic granulomatosis in infants, a fetal sepsis caused by a specific pathogen. Klin Wochenschr. 1951:29:29.

28. McLauchlin J. Human listeriosis in Britain, 1967-85, a summary of 722 cases. 1. Listeriosis during pregnancy and in the newborn. Epidemiol Infect. 1990;104:181-9.

29. Becroft DM, Farmer K, Seddon RJ, Sowden R, Stewart JH, Vines A, et al. Epidemic listeriosis in the newborn. Br Med J. 1971:3:747-51.

30. Bortolussi R, McGregor DD, Kongshavn PA, Galsworthy S, Albritton W, Davies JW, et al. Host defense mechanisms to perinatal and neonatal Listeria monocytogenes infection. Surv Synth Pathol Res. 1984;3:311-32.

31. Gray JW, Barrett JF, Pedler SJ, Lind T. Faecal carriage of listeria during pregnancy. Br J Obstet Gynaecol. 1993;100:873-4.

32. Pezeshkian R, Fernando N, Carne CA, Simanowitz MD. Listeriosis in mother and fetus during the first trimester of pregnancy. Case report. $\mathrm{Br}$ J Obstet Gynaecol. 1984;91:85-6.

33. Lamont RF, Sobel J, Mazaki-Tovi S, Kusanovic JP, Vaisbuch E, Kim SK, et al. Listeriosis in human pregnancy: a systematic review. J Perinat Med. 2011:39(3):227-36.

34. Linnan MJ, Mascola L, Lou XD, Goulet V, May S, Salminen C, et al. Epidemic listeriosis associated with Mexican-style cheese. N Engl J Med. 1988;319:823-8.

35. Fleming DW, Cochi SL, MacDonald KL, Brondum J, Hayes PS, Plikaytis BD, et al. Pasteurized milk as a vehicle of infection in an outbreak of listeriosis. N Engl J Med. 1985;312:404-7.

36. Mackiw E, Modzelewska M, Maka L, Sciezynska H, Pawłowska K, Postupolski J, Korsak D. Antimicrobial resistance profiles of Listeria monocytogenes isolated from ready-to-eat products in Poland in 2007-2011. Food Control. 2015;59(2016):7-11.

37. Du XJ, Zhang X, Wang XY, Su YL, Li P, Wang S. Isolation and characterization of Listeria monocytogenes in Chinese food obtained from the central area of China. J Food Control. 2016:74(2017):9-16.

38. Steven AL, Mark EB, Paula JF, Daniel LF, Richard JM. Antimicrobial resistance of Listeria monocytogenes isolated from a poultry further processing plant. Food Borne Pathog Dis. 2008;5(3):253-9.

39. Nolla M, Kletab S, Al Dahouk S. Antibiotic susceptibility of 259 Listeria monocytogenes strains isolated from food, food-processing plants and human samples in Germany. J Infect Public Health. 2018;11(2018):572-7.

40. Sakaridis I, Soultos N, lossifidou E, Papa A, Ambrosiadis I, Koidis P. Prevalence and antimicrobial resistance of Listeria monocytogenes isolated in chicken slaughterhouses in Northern Greece. J Food Prot. 2011;74(6):1017-21

\section{Publisher's Note}

Springer Nature remains neutral with regard to jurisdictional claims in published maps and institutional affiliations. 